Article

\title{
Association of the Rheumatoid Arthritis Severity Variant rs26232 with the Invasive Activity of Synovial Fibroblasts
}

\author{
Emma R Dorris ${ }^{1, *} \mathbb{C}$, Eimear Linehan ${ }^{1}$, Michelle Trenkmann ${ }^{1} \oplus$, Douglas J Veale ${ }^{1}$, \\ Ursula Fearon ${ }^{2}$ and Anthony G. Wilson ${ }^{1}$ (D) \\ 1 University College Dublin Centre for Arthritis Research, Conway Institute, University College Dublin, \\ Dublin D04 W6F6, Ireland; linehae@tcd.ie (E.L.); michelle.trenkmann@nature.com (M.T.); \\ douglas.veale@ucd.ie (D.J.V.); gerry.wilson@ucd.ie (A.G.W.) \\ 2 Molecular Rheumatology, School of Medicine, Trinity Biomedical Sciences Institute, Trinity College Dublin, \\ Dublin D06 R590, Ireland; fearonu@tcd.ie \\ * Correspondence: emma.dorris@ucd.ie; Tel.: +353-1-7166-801
}

Received: 19 August 2019; Accepted: 21 October 2019; Published: 22 October 2019

check for updates

\begin{abstract}
C5orf30, is associated with the susceptibility to and severity of rheumatoid arthritis (RA). Here, we investigate the relationship between this variant and the biological activities of rheumatoid arthritis synovial fibroblasts (RASFs). RASFs were isolated from the knee joints of 33 RA patients. The rs26232 genotype was determined and cellular migration, invasion, and apoptosis were compared using in vitro techniques. The production of adhesion molecules, chemokines, and proteases was measured by ELISA or flow cytometry. Cohort genotypes were CC $n=16$; CT $n=14$; TT $n=3$. In comparison with the RASFs of the CT genotype, the CC genotype showed a 1.48-fold greater invasiveness in vitro $(p=0.02), 1.6$-fold higher expression intracellular adhesion molecule (ICAM)- $1(p=0.001)$, and 5-fold IFN- $\gamma$ inducible protein-10 (IP-10) $(p=0.01)$. There was no association of the rs 26232 genotype with the expression levels of either total C5orf30 mRNA or any of the three transcript variants. The rs26232 C allele, which has previously been associated with both the risk and severity of RA, is associated with greater invasive activity of RASFs in vitro, and with higher expression of ICAM-1 and IP-10. In resting RASFs, rs26232 is not a quantitative trait locus for C5orf30 mRNA, indicating a more complex mechanism underlying the genotype-phenotype relationship.
\end{abstract}

Keywords: rheumatoid arthritis; synovium; fibroblasts; genetics; C5orf30; genotype-phenotype

\section{Introduction}

Genetic variants in C5orf30 have been associated with the risk of several autoimmune diseases, including rheumatoid arthritis (RA) [1,2]. The rs 26232 variant, located in the first intron, is also associated with the severity of radiological damage in RA [3]. The gene encodes a 206 amino acid protein that is only present in the vertebrae and is highly conserved across species. The expression of C5orf30 is highest in RA synovial fibroblasts (RASFs) and macrophages, key mediators of inflammation and tissue damage in RA [4]. Inhibition of C5orf30 in RASFs results in increased invasive and migratory activities in vitro, and in the collagen-induced arthritis model results in more severe inflammation and joint damage [5]. In macrophages, proinflammatory signals such as tumour necrosis factor (TNF) and lipopolysaccharide (LPS) reduce C5orf30 expression via a c-Jun N-terminal kinase mediated mechanism; furthermore, C5orf30 enhances the resolution of inflammation and wound repair functions mediated by M2 macrophages [6]. 
Most genetic variants associated with RA risk have relatively modest effects on gene expression in a restricted number of cell types: an RA-associated variant in TRAF1 is associated with approximately 2-fold lower expression of TRAF1 in CD8 T cells and macrophages, with consequent higher production of pro-inflammatory cytokines including TNF and interleukin (IL)-6 [7]; a polymorphism in the IL-6 promoter, that has been associated with juvenile idiopathic arthritis, is an expression quantitative trait locus (eQTL) for IL-6 in synovial fibroblasts but not CD14+ monocytes [8]. These data highlight that genotype-phenotype associations may be cell-type-specific.

The biological mechanisms underlying the genetic associations of rs26232 with RA risk and severity are unknown. We hypothesised that, given the effects of C5orf30 on RASF biology, the association of rs26232 arises from allelic-associated differences in the tissue-damaging activities of RASFs. We tested this hypothesis using RASFs from knee joints, using in vitro assays to compare these activities in cells of differing rs26232 genotypes.

\section{Materials and Methods}

\subsection{Isolation and Culture of RASF}

Synovial biopsies were obtained from the knee joints of 44 RA donors. Two donors (both TT genotype) could not be used in functional assays due to low density and slow doubling time. Fresh synovial biopsies were digested using $1 \mathrm{mg} / \mathrm{mL}$ collagenase type 1 , as previously described [5]. Dissociated cells were grown to confluence in RPMI1640 medium (Lonza, Basel, Switzerland supplemented with $10 \%(v / v)$ heat-inactivated FBS, penicillin (100 units $/ \mathrm{mL})$, and streptomycin (100 units $/ \mathrm{mL}$ ) before trypsinization and passage. Cells were used at passage 3 to ensure a homogeneous population of fibroblasts.

\section{2. rs26232 Genotyping}

A TaqMan ${ }^{\circledR}$ SNP Genotyping Assay was used to determine rs26232 genotype, as previously described [9]. Genotyping reactions were run on a QuantStudio7 Flex Real-Time PCR System (Applied Biosystems, Waltham, MA, USA) using standard cycling conditions and a post-read allelic discrimination assay. All samples were run in technical duplicate with positive and no-template controls.

\subsection{RASF Invasion}

In vitro invasion of RASF was assayed in a transwell system using the BD BioCoat Matrigel Invasion Chamber, as previously described [10]. Briefly, RASF were harvested by trypsin-EDTA digestion; $2 \times 10^{4}$ cells were resuspended in $500 \mu \mathrm{L}$ of serum-free RPMI and plated in the upper compartment of the Matrigel-coated inserts. The lower compartment was filled with complete, supplemented media, and incubated at $37^{\circ} \mathrm{C}$ for $24 \mathrm{~h}$. The upper surface of the insert was cleaned with a cotton swab to remove noninvading cells and the Matrigel layer, as previously described. Insert were stained with $0.1 \%$ crystal violet. Five fields of invading cells were counted from a $10 \times$ objective magnification (100× total magnification): one random field from each quarter of the membrane and a central field. Cells from each field were added together to calculate the total number of invading cells.

\subsection{RASF Migration}

In vitro invasion of RASF was assayed in a wound repair assay [10]. In 48-well plates, $2 \times 10^{4}$ RASF were seeded per well in technical duplicate. Cells were grown for $48 \mathrm{~h}$ and a single scratch wound was induced through the middle of each well and imaged at $10 \times$ objective magnification (100× total magnification). After $18 \mathrm{~h}$, wells were washed with PBS and fixed with $4 \%$ paraformaldehyde (PFA) prior to staining with crystal violet. Semi-quantitative analysis of cellular repopulation of the wound margins was performed by counting the number of cells migrating into the wound space. This process was repeated for all technical replicates, and these were averaged to determine the number of migrating cells per RASF donor. 


\subsection{RASF Proliferation}

RASF were seeded into 96-well plates at $5 \times 10^{3}$ cells per well in technical triplicate. Cells were incubated in complete media at $37^{\circ} \mathrm{C}$ for $4 \mathrm{~h}$ and $96 \mathrm{~h}$. RASF were washed with PBS and fixed with $4 \%$ PFA prior to staining with crystal violet. Crystal violet was solubilized with $1 \%$ triton $X$ and absorbance was measured at 570nm. Empty (background) well controls were subtracted from the optical density readings. Technical replicates were averaged to determine the number of migrating cells per RASF donor. Proliferation is reported as fold-change optical density at $96 \mathrm{~h}$ compared to the baseline $(4 \mathrm{~h})$.

\subsection{Flow Cytometry}

RASF were plated into six-well plates at $1 \times 10^{5}$ cells per well in complete media. Cells were incubated at $37^{\circ} \mathrm{C}$ for $48 \mathrm{~h}$. RASF were incubated with $0.3 \mu \mathrm{g} / \mathrm{mL}$ of phycoerythrin-conjugated mouse monoclonal anti-intracellular adhesion molecule (ICAM)-1 or isotype-matched IgG control (all Becton Dickinson, Franklin Lakes, NJ, USA) for $30 \mathrm{~min}$ at $4{ }^{\circ} \mathrm{C}$. Cells were then washed twice and fixed in $1 \%$ paraformaldehyde, and analysed by flow cytometry (FACS) using a FACScan flow cytometer and Lysis II software (both from Becton Dickinson). Adhesion marker expression was calculated based on the median fluorescence intensity (MFI), with background MFI (unstained samples) subtracted. Technical replicates were averaged to determine the MFI per RASF donor.

\subsection{Cytokine and Protease Production}

Cells $\left(2 \times 10^{4}\right.$ per well) were cultured for $48 \mathrm{~h}$ and the supernatants harvested. Matrix Metalloproteinase 3 (MMP3) and Tissue Inhibitor of Metalloproteinase 3 (TIMP3) were measured by single-plex ELISA (R\&D Systems, Minneapolis, MN, USA), IP10, monocyte chemoattractant protein 1 (MCP1) and macrophage inflammatory protein 1 alpha (MIP1 $\alpha$ ) were measured via multiplex ELISA (Meso-scale discovery, Rockville, MD, USA).

\subsection{Real-Time PCR}

Total mRNA was extracted from cultured RASF and reverse-transcribed. Reverse transcription of $100 \mathrm{ng}$ of total mRNA was carried out using a high-capacity cDNA reverse transcription kit (Applied Biosystems, Waltham, MA, USA), as previously described [6]. Real-time PCR was carried out on a Roche Lightcycler (Basel, Switzerland) under standard cycling conditions. Levels of total C5orf30 mRNA and of each of the three $5^{\prime}$ untranslated transcript variants, variant-1, NM_001316968.1; variant-2, NM_033211.3; and variant-3, NM_001316969.1, were measured (Supplementary Table S1). The housekeeping gene HPRT1 was used as an endogenous control. Relative quantitation $(\triangle \triangle \mathrm{Ct}$ method) of ICAM1, MMP14, CDH11, VCAM, and CTSK was carried out via TaqMan real-time PCR on an Applied Biosystems QuantStudio 7 Flex Real-Time PCR System using standard cycling conditions and 18s rRNA as an endogenous control. Assay IDs can be found in Table S2.

\subsection{Data Analysis}

All data were tested for parametric assumptions. Parametric data were analysed using a one-way ANOVA with Tukey's post hoc test for honest significant difference. Non-parametric data were analysed using a Kruskal-Wallis test. An alpha level of 0.05 was used for all analyses.

\section{Results}

\subsection{Association of the rs26232 CC Genotype with Greater Invasiveness of RASFs In Vitro}

Synovial fibroblasts were isolated from 42 RA knee joints; the distribution of genotypes was CC, 20; CT, 19; TT, 3. In view of the low TT genotype frequency, comparisons were restricted to CC and CT genotypes. There was no difference in proliferation rate $(p=0.980)$ (Figure 1A), nor in the rate of cellular migration ( $p=0.783$ ) (Figure 1B). Invasive activity, as assessed using the Matrigel assay, 
was 1.9-fold higher in CC-genotype RASFs ( $p=0.02$ ) (Figure 1C). Representative images from each genotype are shown in Figure 1D,E.
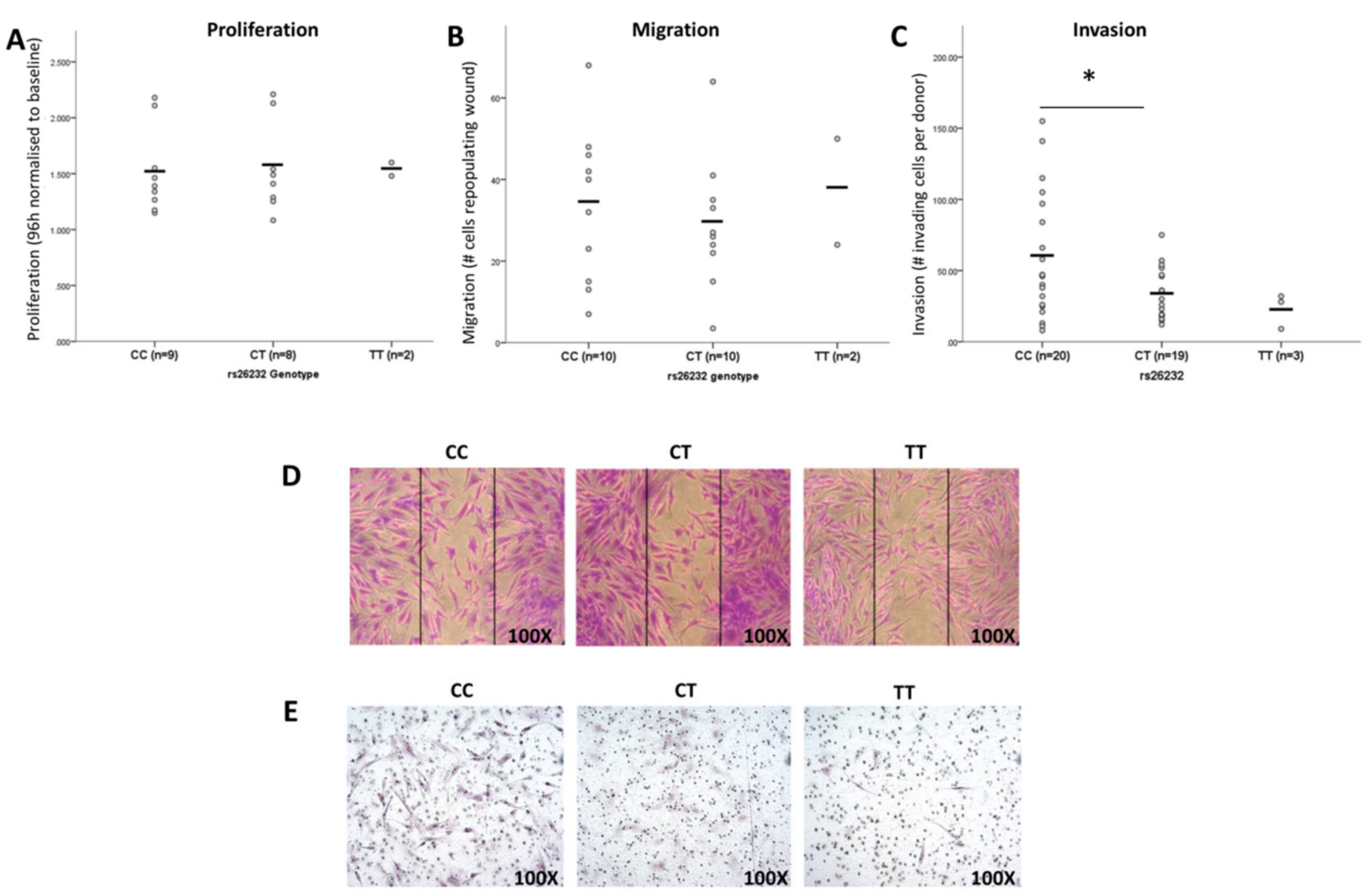

Figure 1. The rs26232 genotype is associated with RASF invasiveness. (A) Proliferation rates of RASFs are not associated with rs26232 genotype $(p=0.980)$. (B) The capacity for cells to migrate was not associated with genotype ( $p=0.783)$. (C) RASF of the CC genotype are more invasive than CT $(p=0.020)$. Representative images of RASF in vitro (D) migration and (E) invasive assays of rs26232 genotypes. Each circle represents the average of an individual donor. Horizontal black bars represent the cohort mean. Statistical significance: ${ }^{*} p<0.05$.

\subsection{Higher ICAM-1, MMP14, and IP-10 Production by RASFs of CC Compared to CT Genotype}

The expression of ICAM-1 was compared between genotype groups using flow cytometry. The CC genotype was associated with 1.5 -fold higher ICAM-1 expression $(p=0.039)$ compared with CT RASFs ( $n=11$ (CC), $n=9$ (CT) for both groups, Figure 2A,B). Relative ICAM-1 gene expression was also higher in CC $(n=14)$ compared to CT $(n=12)$ RASFs $(p=0.44$, Figure $2 C)$, as was the relative gene expression of the matrix metalloprotease MMP14 ( $p=0.021$, Figure 2D). Basal production of the chemokine IP-10 was 5-fold greater in RASFs of the CC genotype compared with CT cells ( $n=4$ each, $p=0.011$, Figure 2C). There was, however, no difference in the basal secretion of MMP3 ( $p=0.457)$, TIMP3 ( $p=0.374)$, MIP1 $(p=0.713)$ or MCP1 $(p=0.982)$ (Supplementary Figure S1A-D, respectively) between CC and CT RASFs ( $n=4$ for both groups). There was no observed difference in relative gene expression of the adhesion markers cadherin $11(\mathrm{CDH} 11, p=0.934)$ and vascular cell adhesion protein 1 (VCAM, $p=0.509)$ nor the protease cathepsin K (CTSK, $p=0.349$ ) (Figure S2A-C). 

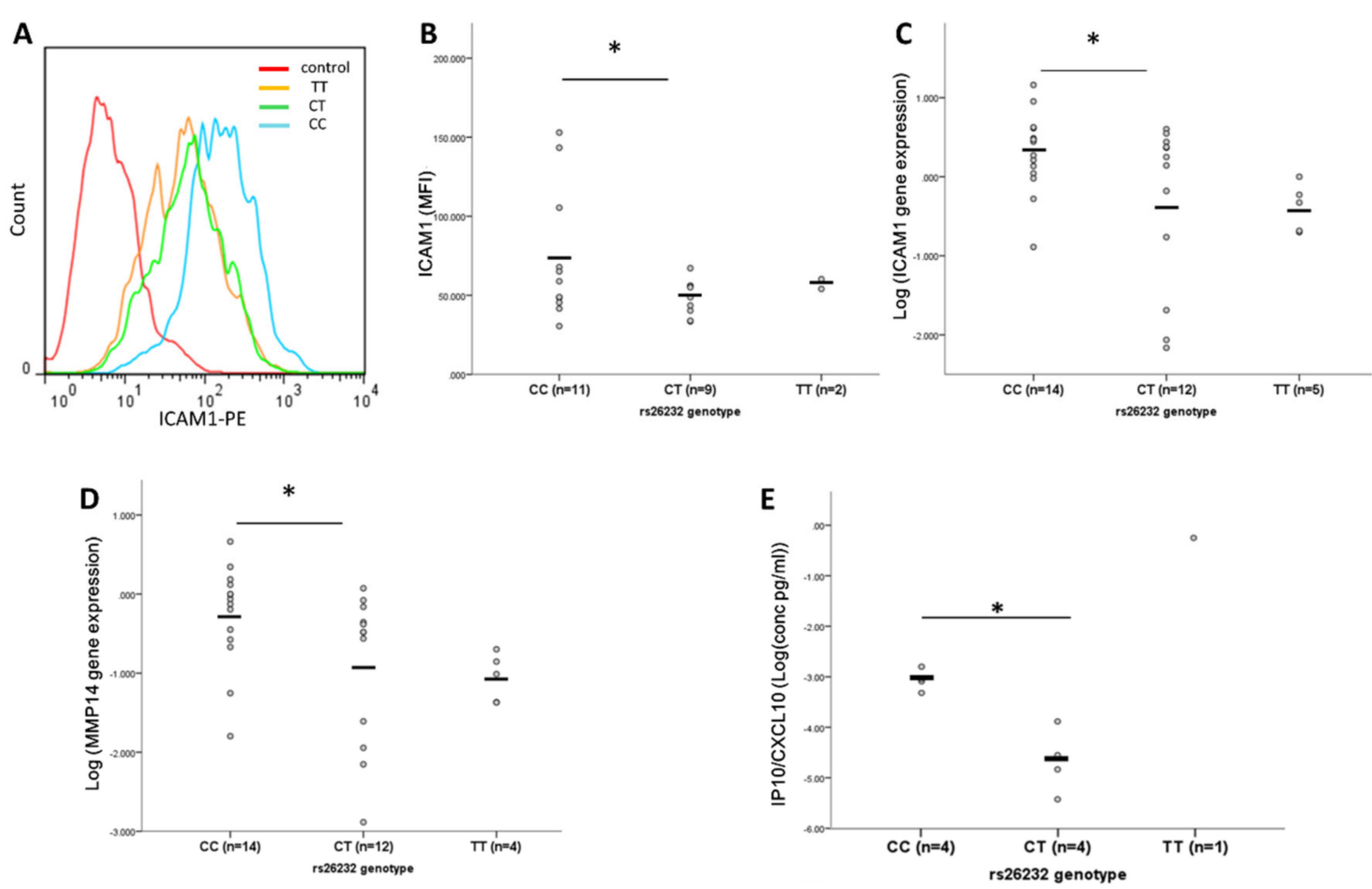

Figure 2. The rs26232 genotype is associated with RASF expression of ICAM1, MMP14 and IP-10. (A) Representative histogram showing ICAM-1 expression by RASFs of different rs26232 genotypes. (B) Expression of ICAM-1 protein is greater in RASFs of the CC compared to CT genotype (1.5-fold, $p=0.039$ ). (C) ICAM1 relative gene expression is higher in CC compared to CT RASFs (2-fold, $p=0.044$ ). (D) MMP14 relative gene expression is higher in CC compared to CT RASFs (1.6-fold, $p=0.021$ )

(E) RASFs of CC genotype produce greater IP10 (CXCL10) compared to CT genotype (5-fold, $p=0.011$ ). Each circle represents an individual donor. The black bar represents the mean. Statistical significance: * $p<0.05$.

\section{3. rs26232 Genotype Is Not Associated with C5orf30 mRNA Expression in RASFs}

The expression of total mRNA and of each of the three $5^{\prime}$ variants was compared between the two rs26232 genotypes ( $n=9$, both groups). There was no difference in either total mRNA levels $(p=0.506)$, or for individual transcripts: variant 1 RefSeq NM 001316968.1 $(p=0.469)$, variant 2 NM 033211.3 $(p=0.352)$, or variant 3 NM $001316969.1(p=0.482)$ (Figure 3A-D, respectively). 
A

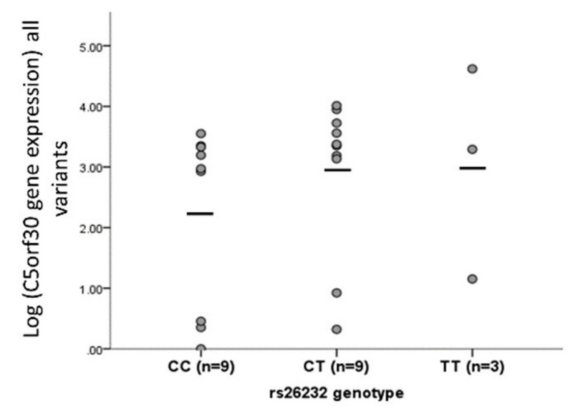

C

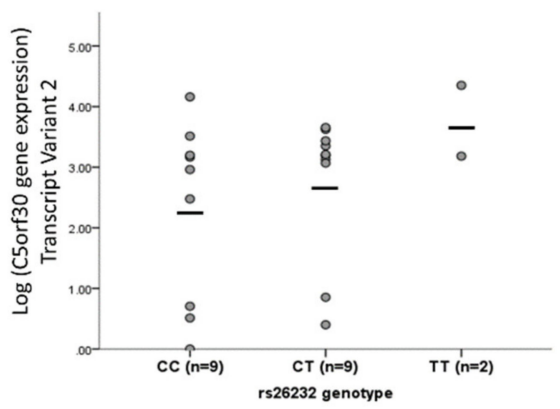

B

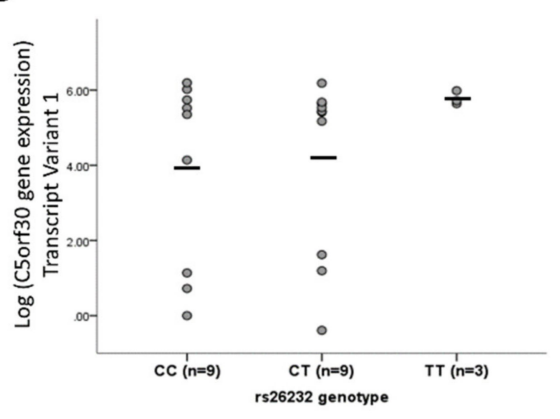

D

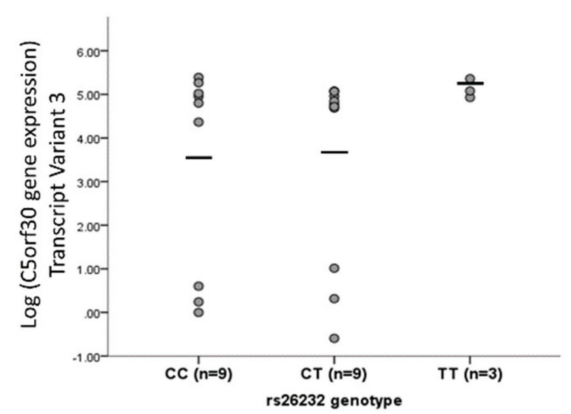

Figure 3. rs26232 is not an eQTL for C5orf30. rs26232 genotype was not associated with (A) total C5orf30 mRNA (all variants) $(p=0.506)$, (B) variant 1 ( $p=0.469),(\mathbf{C})$ variant $2(p=0.352)$, or (D) variant $3(p=0.482)$. Gene expression is analysed using relative quantitation (RQ) to the endogenous control HPRT1. $Y$-axis is mean $\log _{2}$ transformed RQ values per patient RASF line. Each circle represents the average of an individual donor. Horizontal black bars represent the cohort mean.

\section{Discussion}

The $\mathrm{C}$ allele of rs26232 is both a risk and severity variant for RA; it has been linked to radiological damage in the joints of the hands and feet, with a per T allele effect on radiological damage score of 0.9 [3]. In the present study, we examined, using in vitro assays of biological activities, if genotype-phenotype correlations are present in RASFs. Our data reveal significant differences in the invasive activities of RASFs of different rs26232; CC RASFs being more invasive than CT. There were no genotype associations with other pathobiological characteristics of RASFs such as migration, apoptosis, or proliferation. The CC genotype was also associated with higher expression of the adhesion molecule ICAM-1, the membrane-type 1 metalloproteinase MMP14, and the T cell chemokine, IP-10. Notably, however, there was no significant quantitative or qualitative difference in the total C5orf30 mRNA with rs26232 genotype.

The RASF is a central mediator of cartilage damage, producing many disease-relevant effectors including chemokines, adhesion molecules, and proteases [11]; furthermore, it has a semi-transformed phenotype in vitro with loss of contact inhibition, high proliferative activity, and resistance to apoptosis [12,13]. Inhibition of C5orf30 upregulates the invasive activities of RASFs in vitro [5]. The invasive activities of RASFs in vitro have been shown to positively correlate with the rate of radiological damage in the joints of the hands and feet [14]. We have recently reported that RA synovial C5orf30 mRNA levels are inversely correlated with both systemic (DAS28-ESR) and intra-articular (TNF mRNA) measures of disease activity [6]. Our data suggest that the association of the rs 26232 $C$ variant with radiological damage is likely to be related to the higher invasive potential of RASFs. This association may be mechanistically related to the differential expression of several important disease mediators: increased ICAM-1 expression can potentiate interactions with T cells and, in turn, is important for $\mathrm{T}$ cell and fibroblast activation and associated with sustaining both the proinflammatory and invasive processes in the synovium [15-17]. IP-10 is produced by RASFs and synovial macrophages 
and is a chemoattractant for a range of innate and adaptive immune cells [18]. MMP14 has abundant expression in the RA synovium and can be produced by synovial fibroblasts and CD68-positive osteoclasts and macrophages $[19,20]$. MMP14 has also been found to be increased in pathogenic RA fibroblasts, associated with increased invasiveness [21]. Recent studies have increased our understanding of the heterogeneity of fibroblasts in joint tissue and the role of fibroblast subtypes involved in RA pathology [21,22]. We observed no association between CD11 expression and the rs26232 genotype. However, the association between the rs26232 genotype and relative levels of fibroblast subtypes or fibroblast markers such as fibroblast activation protein- $\alpha$ (FAP), Thy- 1 cell surface antigen (THY1), or podoplanin (PDPN) remains unknown.

Most genetic variants linked with common illnesses, such as RA, are in regulatory regions and are eQTLs for one or more nearby genes. There was, however, no evidence that rs 26232 is an eQTL for C5orf30 mRNA in RASF. There had been a report that C5orf30 3' untranslated transcript variants' levels are associated with the rs26232 genotype in peripheral blood leucocytes [23]; however, subsequent data indicated that only $5^{\prime}$ untranslated variants are present in humans. Our data reveal that rs 26232 is not an eQTL for C5orf30 mRNA, or for individual transcript variants, in RASFs. In agreement with these data in RASFs, the Genotype-Tissue Expression Project (GTEx) database does not report rs26232 to be eQTL for C5orf30 in any tissue; however, it is for the nearby transcripts of EIF3KP1, PAM, and PPIP5K2 in a limited number of tissues including the peripheral blood, skeletal muscle, and subcutaneous adipose tissue [24]. The basis of the rs26232 association with both RA radiological severity and RASF behaviour in vitro could arise from several other mechanisms; the eQTL for C5orf30 may only be manifest in the context of the complex inflammatory and hypoxic environment of the RA joint, or be restricted to a different cell type, or could be the result of altered expression of one of the nearby genes. Currently, there is no evidence implicating these loci in RA.

The functional consequences of variants occurring in untranslated regions of genes, such as rs26232, are frequently not immediately obvious. Data from ENCODE (the Encyclopaedia of DNA Elements) have increased our understanding of the impact that sequence variations have on gene expression, but the functional consequences of variants in the $5^{\prime}$ UTR still remain largely uncharacterized $[25,26]$. Annotating non-coding SNPs is more challenging as the consequences of variation are not as well understood [27]. However, a number of studies have shown that a single variant in the noncoding region can have dramatic effects on gene regulation via, for example, disruption of transcription factor binding and modification of chromatin accessibility [28-31]. Recently, it is being realized that regulatory variants can account for the major part of the genetic predisposition to complex traits [32]. In an extensive study of complex diseases including RA, regulatory variants, particularly those in DNase hypersensitivity regions, accounted for much more heritability than coding variants [33]. Rs262332 is predicted to be in a DNase hypersensitivity cluster (UCSC genome browser GRCh38/hg38: http://genome.ucsc.edu/) [34]. Although it is currently difficult to predict the consequences of $5^{\prime}$ UTR variants due to a lack of knowledge of RNA structural complexity and the RNA binding protein (RBP) landscape, data from large-scale cancer genome sequencing projects will likely lead to the uncovering of new biological mechanisms [26,35-37].

\section{Conclusions}

In summary, we present data suggesting that the association of the rs $26232 \mathrm{C}$ allele with RA joint damage is mediated by higher tissue damaging activities of RASFs, and that this is not a mediated by levels of C5orf30 mRNA. A recognised limitation of the study is the reduced number of data points in certain assays. Due to the importance of matched patient RASF lines across assays and passage matching [38], it was not possible for all patient lines to be assayed for all experiments. We prioritised assays based on experimental evidence from previous research $[3,5,15]$, and have been transparent in our data. It is possible that smaller genotype-phenotype effects may not have been observed due to the reduced number of data points for some assays. It will be important to determine if a genotype-phenotype association is also present in synovial macrophages, key cellular mediators in 
RA [4]; they also express C5orf30 at high levels and regulate anti-inflammatory and tissue-protective effects [6].

Supplementary Materials: The following are available online at http:/www.mdpi.com/2073-4409/8/10/1300/s1, Figure S1: rs26232 genotype is not associated with metalloproteases or macrophage chemokines by RASFs. Figure S2: rs26232 genotype is not associated with expression of adhesion markers or cathepsin K. Table S1: Sequences of oligonucleotide primers used in RT-PCR $\left(5^{\prime}-3^{\prime}\right)$. Table S2: TaqMan Assay IDs used in RT-PCR.

Author Contributions: Conceptualization, E.R.D., E.L. and A.G.W.; methodology, E.R.D., E.L., M.T.; formal analysis E.R.D., E.L.; resources, A.G.W., U.F., D.J.V.; writing-original draft preparation, E.R.D. A.G.W.; writing—review and editing, E.R.D., A.G.W., U.F., D.J.V., E.L.; visualization, E.R.D.; supervision, A.G.W., U.F.; project administration, A.G.W.; funding acquisition, E.R.D, A.G.W.

Funding: This research was funded by Arthritis Ireland and the Health Research Board of Ireland under the Medical Research Charities Group-Health Research Board (Grant MRCG-2016-15) and the Irish Research Council (Grant GOIPD/2017/1310).

Conflicts of Interest: The authors declare no conflict of interest. The funders had no role in the design of the study; in the collection, analyses, or interpretation of data; in the writing of the manuscript, or in the decision to publish the results.

\section{References}

1. Stahl, E.A.; Raychaudhuri, S.; Remmers, E.F.; Xie, G.; Eyre, S.; Thomson, B.P.; Li, Y.; Kurreeman, F.A.; Zhernakova, A.; Hinks, A.; et al. Genome-wide association study meta-analysis identifies seven new rheumatoid arthritis risk loci. Nat. Genet. 2010, 42, 508-514. [CrossRef] [PubMed]

2. Cordell, H.J.; Han, Y.; Mells, G.F.; Li, Y.; Hirschfield, G.M.; Greene, C.S.; Xie, G.; Juran, B.D.; Zhu, D.; Qian, D.C.; et al. International genome-wide meta-analysis identifies new primary biliary cirrhosis risk loci and targetable pathogenic pathways. Nat. Commun. 2015, 6, 8019. [CrossRef] [PubMed]

3. Teare, M.D.; Knevel, R.; Morgan, M.D.; Kleszcz, A.; Emery, P.; Moore, D.J.; Conaghan, P.; Huizinga, T.W.; Morgan, A.W.; van der Helm-van Mil, A.H.; et al. Allele-dose association of the C5orf30 rs26232 variant with joint damage in rheumatoid arthritis. Arthritis Rheum. 2013, 65, 2555-2561. [CrossRef] [PubMed]

4. McInnes, I.B.; Schett, G. The pathogenesis of rheumatoid arthritis. New Engl. J. Med. 2011, 365, $2205-2219$. [CrossRef]

5. Muthana, M.; Hawtree, S.; Wilshaw, A.; Linehan, E.; Roberts, H.; Khetan, S.; Adeleke, G.; Wright, F.; Akil, M.; Fearon, U.; et al. C5orf30 is a negative regulator of tissue damage in rheumatoid arthritis. Proc. Natl. Acad. Sci. USA 2015, 112, 11618-11623. [CrossRef]

6. Dorris, E.R.; Tazzyman, S.J.; Moylett, J.; Ramamoorthi, N.; Hackney, J.; Townsend, M.; Muthana, M.; Lewis, M.J.; Pitzalis, C.; Wilson, A.G. The Autoimmune Susceptibility Gene C5orf30 Regulates Macrophage-Mediated Resolution of Inflammation. J. Immunol. 2019, 202, 1069-1078. [CrossRef]

7. Abdul-Sater, A.A.; Edilova, M.I.; Clouthier, D.L.; Mbanwi, A.; Kremmer, E.; Watts, T.H. The signaling adaptor TRAF1 negatively regulates Toll-like receptor signaling and this underlies its role in rheumatic disease. Nat. Immunol. 2017, 18, 26-35. [CrossRef]

8. Noss, E.H.; Nguyen, H.N.; Chang, S.K.; Watts, G.F.; Brenner, M.B. Genetic polymorphism directs IL-6 expression in fibroblasts but not selected other cell types. Proc. Natl. Acad. Sci. USA 2015, 112, 14948-14953. [CrossRef]

9. Dorris, E.R.; Blackshields, G.; Sommerville, G.; Alhashemi, M.; Dias, A.; McEneaney, V.; Smyth, P.; O'Leary, J.J.; Sheils, O. Pluripotency markers are differentially induced by MEK inhibition in thyroid and melanoma BRAFV600E cell lines. Cancer Biol. Ther. 2016, 17, 526-542. [CrossRef]

10. Dorris, E.; O'Neill, A.; Hanrahan, K.; Treacy, A.; Watson, R.W. MARCKS promotes invasion and is associated with biochemical recurrence in prostate cancer. Oncotarget 2017, 8, 72021-72030. [CrossRef]

11. Huber, L.C.; Distler, O.; Tarner, I.; Gay, R.E.; Gay, S.; Pap, T. Synovial fibroblasts: Key players in rheumatoid arthritis. Rheumatology 2006, 45, 669-675. [CrossRef] [PubMed]

12. Niederer, F.; Trenkmann, M.; Ospelt, C.; Karouzakis, E.; Neidhart, M.; Stanczyk, J.; Kolling, C.; Gay, R.E.; Detmar, M.; Gay, S.; et al. Down-regulation of microRNA-34a* in rheumatoid arthritis synovial fibroblasts promotes apoptosis resistance. Arthritis Rheum. 2012, 64, 1771-1779. [CrossRef] 
13. Muller-Ladner, U.; Kriegsmann, J.; Franklin, B.N.; Matsumoto, S.; Geiler, T.; Gay, R.E.; Gay, S. Synovial fibroblasts of patients with rheumatoid arthritis attach to and invade normal human cartilage when engrafted into SCID mice. Am. J. Pathol. 1996, 149, 1607-1615. [PubMed]

14. Tolboom, T.C.; van der Helm-Van Mil, A.H.; Nelissen, R.G.; Breedveld, F.C.; Toes, R.E.; Huizinga, T.W. Invasiveness of fibroblast-like synoviocytes is an individual patient characteristic associated with the rate of joint destruction in patients with rheumatoid arthritis. Arthritis Rheum. 2005, 52, 1999-2002. [CrossRef] [PubMed]

15. Fearon, U.; Mullan, R.; Markham, T.; Connolly, M.; Sullivan, S.; Poole, A.R.; FitzGerald, O.; Bresnihan, B.; Veale, D.J. Oncostatin $\mathrm{M}$ induces angiogenesis and cartilage degradation in rheumatoid arthritis synovial tissue and human cartilage cocultures. Arthritis Rheum. 2006, 54, 3152-3162. [CrossRef] [PubMed]

16. Nakatsuka, K.; Tanaka, Y.; Hubscher, S.; Abe, M.; Wake, A.; Saito, K.; Morimoto, I.; Eto, S. Rheumatoid synovial fibroblasts are stimulated by the cellular adhesion to T cells through lymphocyte function associated antigen-1/intercellular adhesion molecule-1. J. Rheumatol. 1997, 24, 458-464.

17. Hanyuda, M.; Kasama, T.; Isozaki, T.; Matsunawa, M.M.; Yajima, N.; Miyaoka, H.; Uchida, H.; Kameoka, Y.; Ide, H.; Adachi, M. Activated leucocytes express and secrete macrophage inflammatory protein-1 $\alpha$ upon interaction with synovial fibroblasts of rheumatoid arthritis via a $\beta$ 2-integrin/ICAM-1 mechanism. Rheumatology 2003, 42, 1390-1397. [CrossRef]

18. Hanaoka, R.; Kasama, T.; Muramatsu, M.; Yajima, N.; Shiozawa, F.; Miwa, Y.; Negishi, M.; Ide, H.; Miyaoka, H.; Uchida, H.; et al. A novel mechanism for the regulation of IFN-gamma inducible protein-10 expression in rheumatoid arthritis. Arthritis Res. Ther. 2003, 5, R74-R81. [CrossRef]

19. Pap, T.; Shigeyama, Y.; Kuchen, S.; Fernihough, J.K.; Simmen, B.; Gay, R.E.; Billingham, M.; Gay, S. Differential expression pattern of membrane-type matrix metalloproteinases in rheumatoid arthritis. Arthritis Rheum. Off. J. Am. Coll. Rheumatol. 2000, 43, 1226-1232. [CrossRef]

20. Konttinen, Y.; Ceponis, A.; Takagi, M.; Ainola, M.; Sorsa, T.; Sutinen, M.; Salo, T.; Ma, J.; Santavirta, S.; Seiki, M. New collagenolytic enzymes/cascade identified at the pannus-hard tissue junction in rheumatoid arthritis: Destruction from above. Matrix Biol. 1998, 17, 585-601. [CrossRef]

21. Mizoguchi, F.; Slowikowski, K.; Wei, K.; Marshall, J.L.; Rao, D.A.; Chang, S.K.; Nguyen, H.N.; Noss, E.H.; Turner, J.D.; Earp, B.E.; et al. Functionally distinct disease-associated fibroblast subsets in rheumatoid arthritis. Nat. Commun. 2018, 9, 789. [CrossRef] [PubMed]

22. Croft, A.P.; Campos, J.; Jansen, K.; Turner, J.D.; Marshall, J.; Attar, M.; Savary, L.; Wehmeyer, C.; Naylor, A.J.; Kemble, S.; et al. Distinct fibroblast subsets drive inflammation and damage in arthritis. Nature 2019, 570, 246-251. [CrossRef] [PubMed]

23. Zhang, X.; Joehanes, R.; Chen, B.H.; Huan, T.; Ying, S.; Munson, P.J.; Johnson, A.D.; Levy, D.; O'Donnell, C.J. Identification of common genetic variants controlling transcript isoform variation in human whole blood. Nat. Genet. 2015, 47, 345-352. [CrossRef] [PubMed]

24. eGTEx Project. Enhancing GTEx by bridging the gaps between genotype, gene expression, and disease. Nat. Genet. 2017, 49, 1664-1670. [CrossRef]

25. Consortium, E.P. An integrated encyclopedia of DNA elements in the human genome. Nature 2012, $489,57$. [CrossRef]

26. Robert, F.; Pelletier, J. Exploring the Impact of Single-Nucleotide Polymorphisms on Translation. Front Genet 2018, 9, 507. [CrossRef]

27. Nishizaki, S.S.; Boyle, A.P. Mining the Unknown: Assigning Function to Noncoding Single Nucleotide Polymorphisms. Trends Genet 2017, 33, 34-45. [CrossRef]

28. McDaniell, R.; Lee, B.-K.; Song, L.; Liu, Z.; Boyle, A.P.; Erdos, M.R.; Scott, L.J.; Morken, M.A.; Kucera, K.S.; Battenhouse, A. Heritable individual-specific and allele-specific chromatin signatures in humans. Science 2010, 328, 235-239. [CrossRef]

29. Maurano, M.T.; Humbert, R.; Rynes, E.; Thurman, R.E.; Haugen, E.; Wang, H.; Reynolds, A.P.; Sandstrom, R.; $\mathrm{Qu}, \mathrm{H}$.; Brody, J. Systematic localization of common disease-associated variation in regulatory DNA. Science 2012, 337, 1190-1195. [CrossRef]

30. Schaub, M.A.; Boyle, A.P.; Kundaje, A.; Batzoglou, S.; Snyder, M. Linking disease associations with regulatory information in the human genome. Genome Res. 2012, 22, 1748-1759. [CrossRef] 
31. Kasowski, M.; Grubert, F.; Heffelfinger, C.; Hariharan, M.; Asabere, A.; Waszak, S.M.; Habegger, L.; Rozowsky, J.; Shi, M.; Urban, A.E. Variation in transcription factor binding among humans. Science 2010, 328, 232-235. [CrossRef] [PubMed]

32. He, H.; Li, W.; Liyanarachchi, S.; Srinivas, M.; Wang, Y.; Akagi, K.; Wang, Y.; Wu, D.; Wang, Q.; Jin, V.; et al. Multiple functional variants in long-range enhancer elements contribute to the risk of SNP rs965513 in thyroid cancer. Proc. Natl. Acad. Sci. 2015, 112, 6128-6133. [CrossRef] [PubMed]

33. Gusev, A.; Lee, S.H.; Trynka, G.; Finucane, H.; Vilhjálmsson, B.J.; Xu, H.; Zang, C.; Ripke, S.; Bulik-Sullivan, B.; Stahl, E. Partitioning heritability of regulatory and cell-type-specific variants across 11 common diseases. Am. J. Hum. Genet. 2014, 95, 535-552. [CrossRef] [PubMed]

34. Kent, W.J.; Sugnet, C.W.; Furey, T.S.; Roskin, K.M.; Pringle, T.H.; Zahler, A.M.; Haussler, D. The Human Genome Browser at UCSC. Genome Res. 2002, 12, 996-1006. [CrossRef]

35. Bisogno, L.S.; Keene, J.D. RNA regulons in cancer and inflammation. Curr. Opin. Genet. Dev. 2018, 48, 97-103. [CrossRef]

36. Wang, T.; Chen, Y.-H.; Hong, H.; Zeng, Y.; Zhang, J.; Lu, J.-P.; Jeansonne, B.; Lu, Q. Increased nucleotide polymorphic changes in the $5^{\prime}$-untranslated region of $\delta$-catenin (CTNND2) gene in prostate cancer. Oncogene 2009, 28, 555. [CrossRef]

37. Corradin, O.; Saiakhova, A.; Akhtar-Zaidi, B.; Myeroff, L.; Willis, J.; Cowper-Sal-lari, R.; Lupien, M.; Markowitz, S.; Scacheri, P.C. Combinatorial effects of multiple enhancer variants in linkage disequilibrium dictate levels of gene expression to confer susceptibility to common traits. Genome Res. 2014, 24, 1-13. [CrossRef]

38. Neumann, E.; Riepl, B.; Knedla, A.; Lefèvre, S.; Tarner, I.H.; Grifka, J.; Steinmeyer, J.; Schölmerich, J.; Gay, S.; Müller-Ladner, U. Cell culture and passaging alters gene expression pattern and proliferation rate in rheumatoid arthritis synovial fibroblasts. Arthritis Res. Ther. 2010, 12, R83. [CrossRef]

(C) 2019 by the authors. Licensee MDPI, Basel, Switzerland. This article is an open access article distributed under the terms and conditions of the Creative Commons Attribution (CC BY) license (http://creativecommons.org/licenses/by/4.0/). 